\title{
Clinical use of venovenous extracorporeal membrane oxygenation
}

\author{
George WY Ng *, Henry J Yuen, KC Sin, Anne KH Leung, KW Au Yeung, KY Lai
}

This article was published on 17 Mar 2017 at www.hkmj.org.

\section{A B S T R A C T}

Extracorporeal membrane oxygenation has been used clinically for more than 40 years. The technique provides respiratory and/or circulatory support via venovenous and veno-arterial configurations, respectively. We review the basic physiological principles of extracorporeal membrane oxygenation systems in venovenous extracorporeal membrane oxygenation. Clinical aspects including patient selection, equipment, setup, and specific patient management are outlined. Pros and cons of the use of extracorporeal membrane oxygenation in respiratory failure are discussed.

\section{Hong Kong Med J 2017;23:168-76}

DOI: 10.12809/hkmj166070

GWY Ng *, FCICM, FHKAM (Medicine)

HJ Yuen, FHKCA(Intensive Care), FHKAM (Anaesthesiology)

KC Sin, FHKCP, FHKAM (Medicine)

AKH Leung, FCICM, FHKAM (Anaesthesiology)

KW Au Yeung, FCICM, FHKAM (Anaesthesiology)

KY Lai, FRCP (Edin), FHKAM (Medicine)

Department of Intensive Care, Queen Elizabeth Hospital, Jordan, Hong Kong

* Corresponding author: georgeng77@yahoo.com

\section{Introduction}

Extracorporeal membrane oxygenation (ECMO) provides temporary extracorporeal support of the respiratory and/or cardiac system for patients who fail to respond to conventional therapies, buying time for recovery from the underlying condition, and for specific treatment to take effect. The concept and technology of ECMO originated from cardiopulmonary bypass that was first used in $1953 .{ }^{1}$ The first case of successful ECMO support in an adult patient was published by Hill et al in $19722^{2,3}$ Currently, ECMO use is not confined to the operating theatre, but has been extended to the intensive care unit and during inter-hospital transfer.

According to the Extracorporeal Life Support Organization (ELSO) Registry report, 86287 patients received extracorporeal life support (ECLS) globally (up to January 2017). ${ }^{4}$ The majority of patients were neonates $(44.8 \%)$, while $24.1 \%$ were children and $31.1 \%$ were adults. The types of ECLS included respiratory support (58.4\%), cardiac support (31.9\%), and extracorporeal cardiopulmonary resuscitation $(9.7 \%){ }^{4}$

\section{Types of extracorporeal membrane oxygenation}

There are two main types of ECMO configuration: venovenous (VV) and veno-arterial (VA)VV-ECMO provides solely lung support, while VA-ECMO provides both heart and lung support. Depending on the clinical indications and disease progress, the ECMO circuit can be interchanged between VV and VA, from VV to high-flow VV or from VV to veno-arterial-venous ECMO.

\section{Configuration of extracorporeal membrane oxygenation}

The ECMO circuit consists of an access cannula that drains deoxygenated venous blood from the patient, a pump, an artificial lung (oxygenator) that provides oxygenation and carbon dioxide $\left(\mathrm{CO}_{2}\right)$ removal, a heat exchanger, and a return cannula that returns oxygenated blood via a central vein (ie VV-ECMO) or major artery (ie VA-ECMO).

\section{Venovenous extracorporeal membrane oxygenation}

The technique VV-ECMO provides only lung support (Fig 1a). The circuit is connected in series with the right heart and the lungs with the access cannula commonly inserted at the femoral vein. Deoxygenated blood is drained from the venous circulation by a motor pump. The deoxygenated blood then passes through an oxygenator where oxygen diffuses across the oxygenator membrane into the blood. The oxygenated blood then returns to the right heart via a return cannula, placed at the femoral vein or the right internal jugular vein.

\section{High-flow venovenous extracorporeal membrane oxygenation}

The maximal blood flow that can be achieved in an ECMO system is determined by elements of the Hagen-Poiseuille equation, of which the key factor is the cannula size. In situations where maximal blood flow is unable to meet the metabolic demand of the 
patient, such as sepsis with high cardiac output or large body size, an additional access cannula is inserted.

\section{Veno-arterial-venous extracorporeal membrane oxygenation}

Patients with acute severe respiratory failure sometimes develop refractory shock due to severe sepsis and/or myocardial ischaemia. In this case, veno-arterial-venous ECMO can provide both respiratory and circulatory support (Fig 1b). This is achieved by the insertion of an additional return cannula into a major artery in the existing VV-ECMO system, such that a proportion of the oxygenated blood is diverted to the arterial circulation to support organ perfusion.

\section{Physiology of the extracorporeal membrane oxygenation system}

In the native lungs, gaseous exchange occurs by diffusion at the blood gas interface in the alveoli. In the ECMO oxygenator, the same principle applies. The efficiency of gaseous exchange depends on the driving force of the gas and the diffusion efficiency. The driving force of a gas is related to the partial pressure difference across the blood gas interface for the individual gas. The efficiency of diffusion depends on the area for diffusion, distance over which gas has to pass, and the diffusion coefficient for the individual

\section{靜脈一靜脈體外膜氧合的臨床使用}

吳榮耀、袁愷寅、冼佳卓、梁結雄、歐陽健華、黎鏡堯

體外膜氧合 (ECMO) 臨床上的應用已經超過 40 年。此技術分別通 過靜脈一靜脈和靜脈一動脈兩種方式為有需要病人進行呼吸和循環支 持。本文回顧靜脈一靜脈 ECMO系統的基本生理學原理, 從臨床角度 概述患者篩選、硬件設備、臨床設置和針對性的患者管理，以及討論 ECMO在應對呼吸衰竭的利弊。

gas. The amount of oxygen delivered by VV-ECMO is influenced by the oxygenator membrane surface area, membrane thickness, haemoglobin level, and ECMO blood flow.

The venous partial pressure of oxygen $\left(\mathrm{PaO}_{2}\right)$ at the blood interface of the oxygenator is around 5.3 $\mathrm{kPa}$, while dry $100 \%$ oxygen $\left(\mathrm{O}_{2}\right)$ runs through the gas interface equivalent to a partial pressure of $101 \mathrm{kPa}$. This provides a partial pressure gradient for oxygen to diffuse across the semipermeable membrane of the oxygenator from the gas interface to the blood interface. ${ }^{5}$ An example is shown in the Box.

In reality, the maximal oxygen transfer capability is also determined by the gas exchange surface area and the amount of disruption to laminar flow as blood passes through the oxygenator. (a)

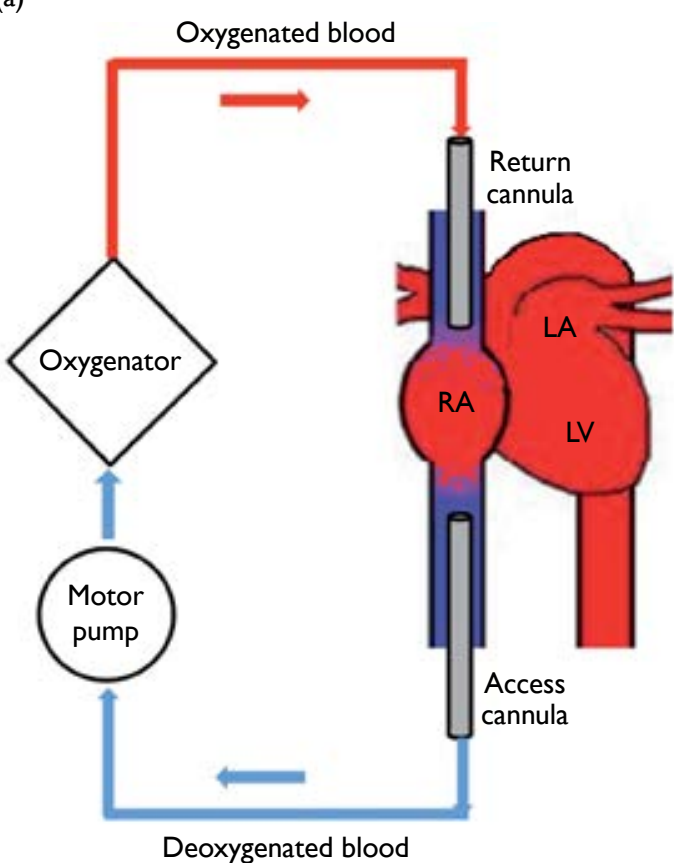

(b)

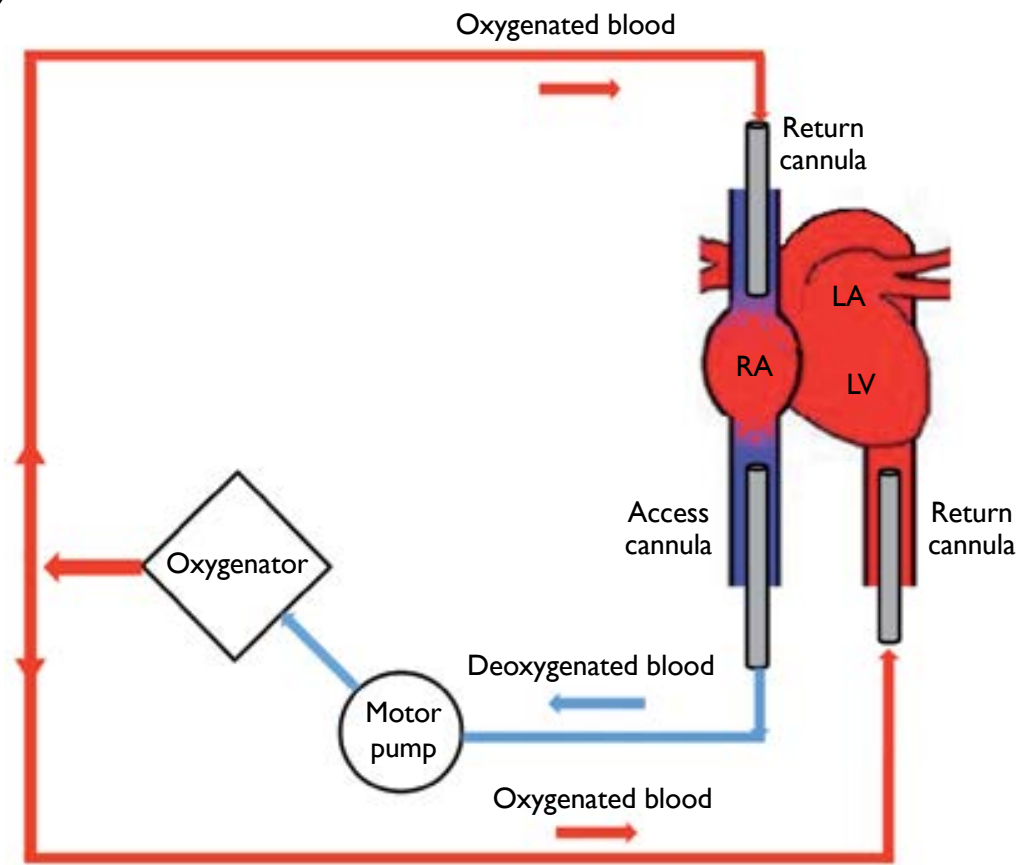

FIG I. Venovenous extracorporeal membrane oxygenation (ECMO) configuration

(a) Venovenous and (b) veno-arterial-venous ECMO circuits

Abbreviations: $L A=$ left atrium; $L V=$ left ventricle; $R A=$ right atrium 
BOX. Oxygen delivery by ECMO as derived from the oxygen flux equation

Abbreviations: $\mathrm{DO}_{2}=$ oxygen delivery; $\mathrm{ECMO}=$ extracorporeal membrane oxygenation; [Hb] = haemoglobin concentration; $\mathrm{PaO}_{2}=$ partial pressure of oxygen; $\mathrm{SaO}_{2}=$ oxygen saturation; I.34 = Hüfner's constant

$\mathrm{O}_{2}$ supplied by ECMO with $4 \mathrm{~L} / \mathrm{min}$ blood flow:

$\mathrm{DO}_{2}=$ blood flow in $\mathrm{dL} \times\left(1.34 \times[\mathrm{Hb}] \times \mathrm{SaO}_{2}+\left(0.023 \times \mathrm{PaO}_{2}\right)\right)$

Assume $[\mathrm{Hb}]=12 \mathrm{~g} / \mathrm{dL} ; \mathrm{SaO}_{2}=100 \%$ (post-oxygenator); ECMO blood flow = $4 \mathrm{~L} / \mathrm{min}$

$\mathrm{O}_{2}$ supplied by ECMO $=40 \times(1.34 \times 12 \times 100 \%+(0.023 \times 101))=736 \mathrm{~mL} / \mathrm{min}$

with the assumption that blood that passes through the ECMO oxygenator achieves full oxygen-carrying capacity, including that of dissolved oxygen

The $\mathrm{O}_{2}$ consumption $\left(\mathrm{VO}_{2}\right)$ is approximately $250 \mathrm{~mL} / \mathrm{min}$ in a VV-ECMO adult patient. ${ }^{6}$ Thus from the above example, the $\mathrm{DO}_{2} / \mathrm{VO}_{2}$ ratio is greater than 2:1 and within the safe range to prevent anaerobic metabolism $\left(\mathrm{DO}_{2}=\right.$ oxygen delivery $)$. If the ECMO blood flow is $4 \mathrm{~L} / \mathrm{min}$ and the cardiac output is $5 \mathrm{~L} / \mathrm{min}, 1 \mathrm{~L}$ of blood that returns to the right heart theoretically passes through the pulmonary circulation and the native sick lungs achieving limited gaseous exchange. Therefore, the final $\mathrm{O}_{2}$ saturation will not be $100 \%$ due to this admixture.

Active sepsis results in both increased $\mathrm{VO}_{2}$ and increased cardiac output. In most situations, the native sick lungs can still partially serve the function of gaseous exchange and contribute to $\mathrm{DO}_{2}$. Nonetheless when $\mathrm{DO}_{2} / \mathrm{VO}_{2}$ ratio falls below $2: 1$, anaerobic respiration occurs with consequent accumulation of lactate.

Similar to $\mathrm{O}_{2}, \mathrm{CO}_{2}$ can pass through the oxygenator membrane from the blood to the gas interface by diffusion; $\mathrm{CO}_{2}$ has a higher diffusion coefficient than $\mathrm{O}_{2}$ because of its greater blood solubility. As a result, $\mathrm{CO}_{2}$ transfer is 6 times faster than $\mathrm{O}_{2}$ for the same membrane thickness and pressure gradient. Unlike $\mathrm{O}_{2}, \mathrm{CO}_{2}$ transfer is independent of blood flow. The most important limiting factor for $\mathrm{CO}_{2}$ transfer is the relative concentration of $\mathrm{CO}_{2}$ on either side of the membrane. The partial pressure of $\mathrm{CO}_{2}$ in the blood interface is about $6 \mathrm{kPa}$, but there is negligible $\mathrm{CO}_{2}$ in the gas interface of the membrane. It is possible to remove $250 \mathrm{~mL} / \mathrm{min}$ of $\mathrm{CO}_{2}$ with an ECMO blood flow of $<1 \mathrm{~L} /$ min by flushing the membrane lung with fresh gas flow (Sweep gas) to maintain the high $\mathrm{CO}_{2}$ gradient across the membrane.

\section{Venovenous extracorporeal membrane oxygenation: patient selection and clinical evidence}

Mechanical ventilation is the mainstay treatment for respiratory failure in patients with severe acute respiratory distress syndrome (ARDS). The use of positive pressure ventilation, however, can induce lung injury by over-distension of the alveoli or from cyclical collapsing and re-opening of the alveoli. Moreover, ventilation-induced lung injury can trigger a systemic inflammatory response and result in multi-organ failure. ${ }^{7}$

A lung protective ventilation strategy is proven to reduce ventilator-associated lung injury and mortality in ARDS patients. ${ }^{7}$ Yet in clinical practice, it is often difficult to adhere to these ventilator parameters without causing significant hypercarbia and respiratory acidosis. Of note, ECMO can overcome this challenge as it provides an additional source of blood oxygenation and $\mathrm{CO}_{2}$ removal through the extracorporeal circuit and oxygenator, and allows lung rest. Table $1^{8}$ lists the common indications for and contra-indications to VV-ECMO.

Careful patient selection for VV-ECMO is crucial to achieve a favourable outcome, balancing the perceived benefit of improving oxygenation with the risk of complications during ECMO initiation and maintenance. Alternatives to ECMO including prone ventilation and inhaled nitric oxide are also considered in this risk-benefit assessment. Indeed, VV-ECMO for severe ARDS is currently established as a sound rescue therapy rather than a standard of care. The landmark VV-ECMO trial (CESAR: Conventional ventilatory support versus Extracorporeal membrane oxygenation for Severe Adult Respiratory failure) was the first to report improved survival in patients with severe ARDS transferred to an ECMO referral centre compared with those who received conventional treatment. ${ }^{9}$ This-together with good outcomes from Australasian, ${ }^{10}$ French, ${ }^{11}$ and Italian ${ }^{12}$ experiences in patients with H1N1-associated ARDS-has contributed to the heightened interest in VV-ECMO and its increased use during and after the H1N1 pandemic.

The results of the CESAR trial could be interpreted as a recommendation for transfer to an ECMO-capable centre, where the improved outcomes may have been from the total care at the ECMO centre, and not from ECMO therapy alone. ${ }^{9}$ Nonetheless no randomised controlled trial has 
TABLE I. Indications for and contra-indications to venovenous extracorporeal membrane oxygenation ${ }^{8}$

\begin{tabular}{|c|c|}
\hline Indication & Contra-indication \\
\hline $\begin{array}{l}\text { - Hypoxic respiratory failure due to any cause when the } \\
\text { predicted mortality risk is }>80 \%\left(\mathrm{PaO}_{2} / \mathrm{FiO}_{2}<100 \text { on } \mathrm{FiO}_{2}\right. \\
>90 \% \text { and/or Murray score } 3-4 \text { despite optimal care for } \\
\geq 6 \text { hours) } \\
\text { - } \mathrm{CO}_{2} \text { retention on mechanical ventilation despite high } \mathrm{P}_{\text {plt }} \\
\left(>30 \mathrm{~cm} \mathrm{H}_{2} \mathrm{O}\right) \\
\text { - Severe air leak syndrome } \\
\text { - Need for intubation in patients on lung transplant list } \\
\text { - Immediate cardiac or respiratory collapse that is } \\
\text { unresponsive to optimal care }\end{array}$ & $\begin{array}{l}\text { - Mechanical ventilation at high settings }\left(\mathrm{FiO}_{2}>90 \%, \mathrm{P}_{\mathrm{plt}}\right. \\
\text { - Unwitnessed cardiac/respiratory arrest } \\
\text { - Disseminated malignancy } \\
\text { - Major pharmacological immunosuppression (absolute } \\
\left.\text { neutrophil count }<400 \mathrm{~mm}^{3}\right) \\
\text { - } \mathrm{CNS} \text { haemorrhage that is recent or expanding } \\
\text { - Non recoverable co-morbidity such as major CNS damage } \\
\text { or terminal malignancy }\end{array}$ \\
\hline
\end{tabular}

Abbreviations: CNS = central nervous system; $\mathrm{CO}_{2}=$ carbon dioxide; $\mathrm{FiO}_{2}=$ fraction of inspired oxygen; $\mathrm{P}_{\text {plt }}=$ plateau pressure; $\mathrm{PaO}_{2}=$ partial pressure of oxygen

TABLE 2. Murray score ${ }^{18}$

\begin{tabular}{|c|c|c|c|c|c|}
\hline \multirow[t]{2}{*}{ Variable } & \multicolumn{5}{|c|}{ Score } \\
\hline & 0 & 1 & 2 & 3 & 4 \\
\hline $\mathrm{PaO}_{2} / \mathrm{FiO}_{2}$ (on $100 \%$ oxygen) in $\mathrm{mm} \mathrm{Hg}$ & $\geq 300$ & $225-299$ & $175-224$ & $100-174$ & $<100$ \\
\hline CXR (quadrant) & Normal & 1 & 2 & 3 & 4 \\
\hline PEEP $\left(\mathrm{cm} \mathrm{H} \mathrm{H}_{2} \mathrm{O}\right)$ & $\leq 5$ & $6-8$ & $9-11$ & $12-14$ & $\geq 15$ \\
\hline Compliance $\left(\mathrm{mL} / \mathrm{cm} \mathrm{H}_{2} \mathrm{O}\right)$ & $\geq 80$ & $60-79$ & $40-59$ & $20-39$ & $\leq 19$ \\
\hline
\end{tabular}

Abbreviations: $\mathrm{CXR}=$ chest $\mathrm{X}$-ray; $\mathrm{FiO}_{2}=$ fraction of inspired oxygen; $\mathrm{PaO}_{2}=$ partial pressure of oxygen; $\mathrm{PEEP}=$ positive endexpiratory pressure

proven that VV-ECMO should be the standard of care for severe ARDS in non-influenza patients. The ongoing ECMO for severe ARDS (EOLIA) trial is a multicentre, international, randomised controlled trial evaluating early ECMO (within 3-6 hours) after the diagnosis of very severe ARDS $\left(\mathrm{PaO}_{2} / \mathrm{FiO}_{2}<80\right.$ $\mathrm{mm} \mathrm{Hg}$, where $\mathrm{FiO}_{2}=$ fraction of inspired oxygen) in patients not responding favourably to optimal ventilation. A positive outcome from this trial may further support the use of VV-ECMO for respiratory failure, and prompt a review of our territory-wide referral network for coordinated transfers to improve patient care. ${ }^{13}$

An ELSO Centre of Excellence recently reported the long-term outcome for patients with respiratory failure or sepsis treated with ECMO from 1995 to 2013 with $64 \%$ survival to discharge and better long-term survival for patients treated for infection. ${ }^{14}$ This suggests that the reversibility of the disease process is an important consideration when selecting appropriate patients for ECMO.

Different ECMO centres have proposed their own selection criteria for ECMO treatment. ${ }^{15,16} \mathrm{~A}$ pretreatment predicting a mortality of higher than $80 \%$ is widely accepted as a cut-off for screening a potential ECMO candidate. In addition, ELSO suggests that this $80 \%$ mortality risk broadly corresponds to a $\mathrm{PaO}_{2} / \mathrm{FiO}_{2}$ of $<100 \mathrm{~mm} \mathrm{Hg}$ on $\mathrm{FiO}_{2}$ $>90 \%$ and/or Murray score of 3-4 despite optimal care for $\geq 6$ hours. $^{8}$ In addition, the longer the duration of mechanical ventilation before initiation of ECMO, the worse the outcome. ${ }^{17}$ It was also reported that ECMO patients had a better survival rate when they were managed in an experienced quaternary referral ECMO centre. ${ }^{9}$

\section{Murray score}

In 1988, Murray et $\mathrm{al}^{18}$ proposed an extended definition of ARDS, taking into account various pathophysiological features of the clinical syndrome. The Murray scoring system includes four components for stratification of the severity of ARDS. Each component is scored from 0 to 4 according to severity (Table $2^{18}$ ). The final mean score is obtained by dividing the collective score by four, which is the number of components used. A score of 0 indicates no lung injury, 1-2.5 indicates mild-to-moderate lung injury, and $>2.5$ indicates the presence of ARDS.

\section{Equipment, setup, and specific patient management}

\section{Equipment}

As an ECLS system, there are three key components of an ECMO circuit-blood pump, oxygenator, and cannula.

The function of the blood pump is to provide the required blood flow to the patient. This can be achieved by means of mechanical (roller pump) or centrifugal force (centrifugal pump). With advances 
in technology, a centrifugal pump has replaced the roller pump in ECMO as it is more durable, lighter, and results in less haemolysis, and less platelet and complement activation. A centrifugal pump is preload sensitive and afterload dependent. 'Preload sensitive' means the blood flow is sensitive to volume at the pump inlet. In the presence of inadequate blood drainage such as in hypovolaemia, the flow reduces automatically. 'Afterload dependent' means the blood flow is also sensitive to resistance at the pump outlet. Flow reduction occurs when postpump resistance increases. Examples include the presence of thrombus in the oxygenator, kinking of the return cannula, and excessive systemic vascular resistance or mean arterial pressure.

The oxygenator was traditionally made of silicone membrane because of their high biocompatibility. It was later replaced by microporous polypropylene hollow fibres with an advantage of lower pressure drop, need for lower priming volume, and better gas exchange efficiency. Direct contact between the gas interface and blood through the microporous fibres, however, results in plasma leakage, which is a serious complication. The newest-generation oxygenator contains multiple hollow fibres that are coated with polymethylpentene and avoids direct contact between the gas interface and blood. Gas transfer is by diffusion. This new oxygenator is more efficient (with lower volume), more effective in gas exchange, causes less platelet and plasma protein loss, and has a thrombo-resistant coating. ${ }^{19}$

An ideal ECMO cannula provides the desired flow with minimal pressure drop, and minimal damage to blood cells or activation of inflammatory response. According to the Hagen-Poiseuille equation, a cannula with the shortest length and the largest diameter offers the greatest flow. Blood in contact with the inner layer of a cannula activates the coagulation and complement cascades, the kallikrein-kinin system, and other inflammatory cells. Currently available cannulas have a special surface coating to minimise the risk of thrombus formation. An example of such coating is a heparincoated surface although there remains a risk of developing heparin-induced thrombocytopenia. Newer technology employs a hydrophilic layer with negatively charged groups to repel negatively charged inflammatory proteins and platelets. ${ }^{20}$

\section{Setup}

Role prioritisation and good communication are the keys for successful ECMO initiation and setup. Informed consent should be obtained from the patient's family. The patient should be well-sedated, and coagulopathy (if any) should be corrected before cannulation.

The cannulation procedure is usually performed at the bedside under aseptic conditions. The Seldinger technique is employed with serial dilatation under ultrasound or fluoroscopic guidance. For VV-ECMO, one common approach is a two-cannula technique with either femoral-jugular or femoral-femoral cannulation. Some centres use a single cannula technique and insert a dual lumen catheter (Avalon Laboratories, Rancho Dominguez [CA], United States) into the right internal jugular vein. If a femoral-jugular approach for the twocannula technique is used, the patient should be placed in the Trendelenburg position. The left internal jugular vein is a less preferred site due to its smaller size and higher risk of vascular injury at the internal jugular-brachiocephalic vein junction. Ultrasound is commonly used during the cannulation procedure to locate the vessel, assess vessel size, and to confirm correct guidewire placement and final position of the cannula. Systemic anticoagulation should be started immediately after cannulation provided there is no absolute contra-indication.

\section{Specific patient management Ventilation strategies}

Patients with severe ARDS often have both hypoxaemia and hypercarbia that make the setting of ventilator parameters difficult. Inappropriate setting of mechanical ventilation can lead to further lung damage including excessive transpulmonary pressure (barotrauma), excessive lung volume inside the alveoli (volutrauma), and shearing stress during repetitive opening and closing of the alveoli (atelectrauma). ${ }^{21}$ Several large randomised controlled trials have proven that a low tidal volume strategy ( $\leq 6 \mathrm{~mL} / \mathrm{kg}$ of ideal body weight) achieves better outcomes than a traditional ventilatory strategy (10-12 mL/kg of ideal body weight ). ${ }^{7,22,23} \mathrm{In}$ addition, maintaining a plateau pressure of $<30 \mathrm{~cm}$ $\mathrm{H}_{2} \mathrm{O}$ minimises the risk of barotrauma. It is hard to achieve these targets in a sick lung using mechanical ventilation alone.

The use of ECMO overcomes the problem as $\mathrm{CO}_{2}$ removal and blood oxygenation take place in an extracorporeal system. This permits complete lung rest with the application of low tidal volume and plateau pressure (ie lung protective ventilation strategy). ${ }^{24}$ One of the ventilation strategies recommended by ELSO guidelines is as follows: pressure-controlled ventilation at positive endexpiratory pressure (PEEP) $15 \mathrm{~cm} \mathrm{H}_{2} \mathrm{O}$ and pressure control above PEEP at $10 \mathrm{~cm} \mathrm{H}_{2} \mathrm{O}$, rate $5 / \mathrm{min}$, inspiratory-to-expiratory time ratio $2: 1$, and $\mathrm{FiO}_{2}$ $50 \%$.

The optimal ventilator strategy for patients on VV-ECMO, especially the level of PEEP, is still controversial. Randomised controlled trials show that in patients where a higher PEEP $\left(14-15 \mathrm{~cm} \mathrm{H}_{2} \mathrm{O}\right)$ was used, there were fewer mechanical ventilator 
days and number of organ failure compared with patients using a lower PEEP $\left(9-10 \mathrm{~cm} \mathrm{H}_{2} \mathrm{O}\right)$. There was, however, no mortality benefit. A criticism of the randomised controlled trials is that they recruited a large proportion of patients in whom PEEP was inappropriate and who consequently did not respond to its application..$^{25-27}$ More importantly, all these studies were performed in non-ECMO settings.

A conservative fluid strategy is commonly adopted in patients on VV-ECMO for ARDS and may be associated with lower mortality, better lung function, and shorter duration of mechanical ventilation. ${ }^{28}$ Nonetheless, volume deficit can lead to ECMO blood flow reduction as the centrifugal pump is preload sensitive. Line shaking can occur if volume depletion has become significant with pump flow reduction.

\section{Renal replacement therapy}

Previous studies showed that $70 \%$ of ECMO patients who developed acute kidney injury had a poorer outcome. ${ }^{29-31}$ Continuous renal replacement therapy (CRRT) is commonly used in ECMO patients for renal support and fluid management. There are various methods for delivering CRRT in ECMO patients: by inserting a new venous cannula for CRRT independent of the ECMO circuit, integrating the haemofiltration filter into the ECMO circuit, or by connecting a CRRT machine to the ECMO circuit (Fig 2). To minimise the risk of air embolism, the CRRT circuit should be connected after the ECMO motor pump. ${ }^{32,33}$ This combination enables a longer filter life and more accurate fluid management. ${ }^{34}$

\section{Sedation}

There are special concerns regarding the choice of sedative agents in ECMO patients. The ECMO circuit tubing absorbs lipophilic drugs. As such, lipophilic sedative agents such as propofol, midazolam, and fentanyl are rapidly removed from the systemic circulation and larger doses are required to achieve the target effect. ${ }^{35,36}$ Medications that are formulated as lipid suspensions, such as propofol, can also corrode the oxygenator membrane, especially when there is a high infusion rate. ${ }^{37}$ These agents should be avoided.

\section{Anticoagulation}

Haemorrhagic and thromboembolic events are common and are the main causes of morbidity and mortality in ECMO patients. Anticoagulation is necessary during ECMO because of the high thrombogenicity associated with blood contact with a non-biological surface. ${ }^{38}$ Close monitoring is nonetheless essential to avoid overanticoagulation. Activated clotting time is frequently used as a pointof-care monitoring of heparin in ECMO patients, ${ }^{39}$ while activated partial thromboplastin time is a conventional method for testing the intrinsic and common coagulation pathways. Unfractionated heparin is widely used as the anticoagulant for ECMO patients although potential complications including bleeding, heparin-induced thrombocytopenia, and tachyphylaxis, may arise. ${ }^{40}$ Bivalirudin, a direct thrombin inhibitor, has been tested in ECMO patients as an alternative to heparin ${ }^{41}$ and been shown to cause less bleeding, be more cost-effective, and results in the need for fewer allogenic transfusions. ${ }^{42}$

\section{Possible complications related to veno- venous extracorporeal membrane oxygenation}

Extracorporeal membrane oxygenation is a complex and high-risk procedure. Medical crises occur rarely

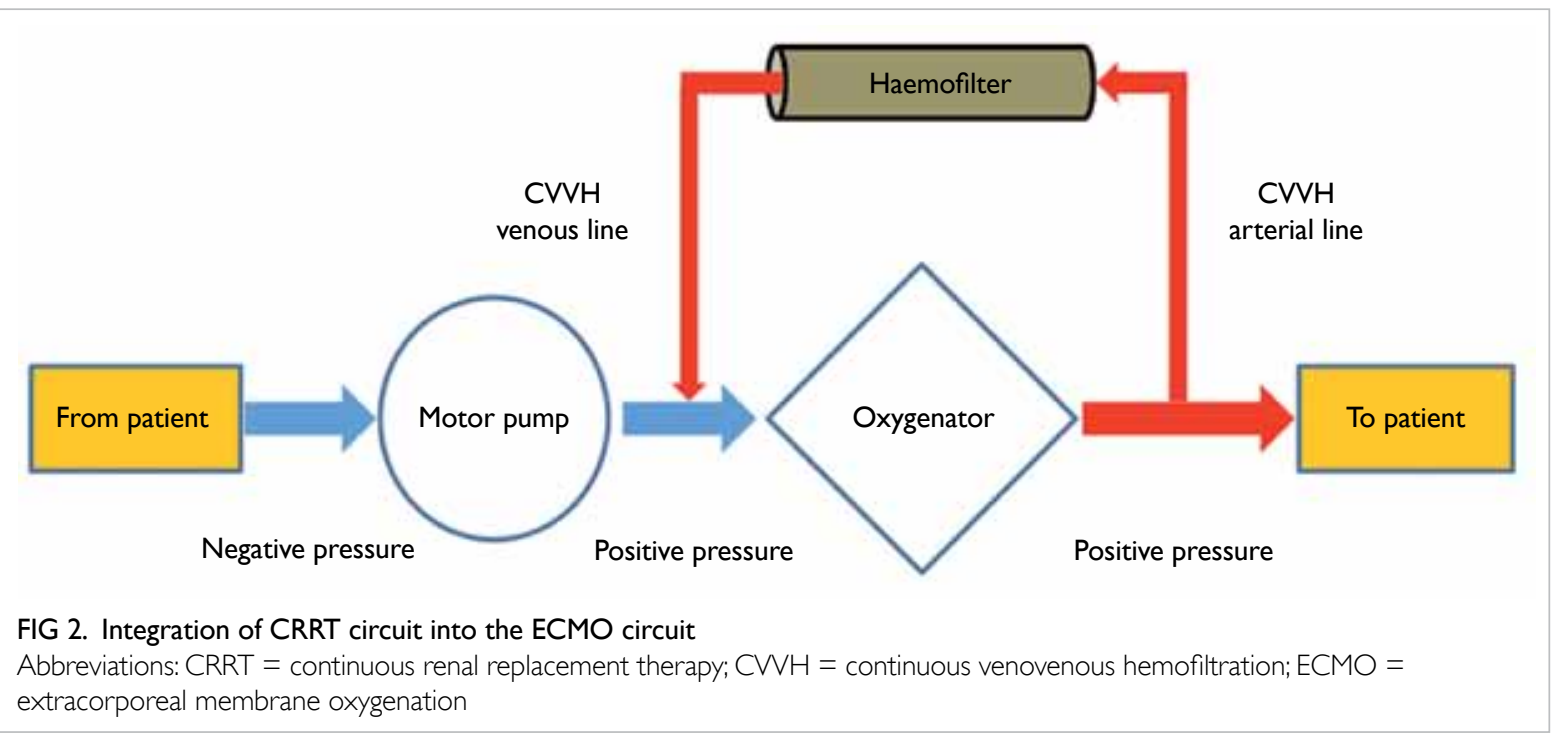


TABLE 3. Possible major complications of venovenous extracorporeal membrane oxygenation ${ }^{4}$

\begin{tabular}{|c|c|}
\hline Complication & Details \\
\hline \multicolumn{2}{|l|}{ Mechanical circuit complications } \\
\hline Air embolism (1.4\%) & $\begin{array}{l}\text { Broken three-way/pigtail (before the motor pump) } \\
\text { Cannula is dislodged or its side holes are exposed }\end{array}$ \\
\hline Oxygenator failure (8.7\%) & $\begin{array}{l}\text { Mechanical breakdown: when the oxygenator membrane is broken or worn off } \\
\text { Functional breakdown: when there are clots/thrombus forming on the surface that impedes gas transfer }\end{array}$ \\
\hline Cannula and tubing (5.8\%) & $\begin{array}{l}\text { Injury: trauma to adjacent organs, eg localised haematoma, pneumothorax, dissection of vessel, oesophageal } \\
\text { perforation, cardiac perforation } \\
\text { Malposition: recirculation occurs when the tips of the return cannula and access cannula are so close that } \\
\text { oxygenated blood from the return cannula drains directly into the access cannula }\end{array}$ \\
\hline Pump (1.5\%) & $\begin{array}{l}\text { Motor failure } \\
\text { Pump head broken }\end{array}$ \\
\hline \multicolumn{2}{|l|}{ Patient-related complications } \\
\hline Severe bleeding & $\begin{array}{l}\text { Bleeding may occur at the cannula site }(12.5 \%) \text {, surgical site }(10.0 \%) \text {, or site of a previous invasive procedure. } \\
\text { Gastrointestinal bleeding }(5.9 \%) \text {, pulmonary haemorrhage }(5.8 \%) \text {, and spontaneous intracranial bleeding } \\
(3.7 \%) \text { may occur }\end{array}$ \\
\hline Cardiovascular & $\begin{array}{l}\text { Myocardial stunning }(1.0 \%) \text { and capillary leak syndrome may occur due to activation of the systemic } \\
\text { inflammatory response secondary to blood contact with a non-biological surface } \\
\text { Cardiac tamponade }(1.7 \%) \\
\text { Cardiac arrhythmia }(10.2 \%)\end{array}$ \\
\hline Pulmonary & $\begin{array}{l}\text { Worsening of respiratory failure due to activation of systemic inflammatory response } \\
\text { Pneumothorax requiring treatment }(8.4 \%)\end{array}$ \\
\hline
\end{tabular}

but can be life-threatening (Table 3). ${ }^{4}$ Making the correct decision hinges on a rapid understanding the situation and the primary cause of the complication.

\section{Weaning from extracorporeal membrane oxygenation}

As the native lung improves, the demand on the extracorporeal system decreases. In general, ECMO weaning can be considered if the patient has substantial signs of native lung recovery, and can tolerate low ECMO support (ie ECMO blood flow $<2.0 \mathrm{~L} / \mathrm{min}$ and lower sweep gas $\mathrm{FiO}_{2}$ to keep peripheral oxygen saturation $>95 \%){ }^{8}$ Decreasing the ECMO blood flow to $<2.0 \mathrm{~L} / \mathrm{min}$, however, risks thrombus formation. As an alternative, a weaning trial can be done by either switching off the sweep gas flow or decreasing the $\mathrm{FiO}_{2}$ to 0.21 . The setting of the mechanical ventilator is adjusted accordingly. Decannulation can be considered if the patient is stable for $>1$ hour following the adjustment. ${ }^{43}$

The ECMO cannulae are removed after heparin infusion has been stopped for more than 60 minutes, and there is no major coagulopathy. Cannulae that were inserted by a cutdown procedure should be removed in the operating theatre as vessel repair is necessary. Those that were inserted percutaneously can be removed at the bedside.

\section{Conclusion}

Venovenous ECMO is considered one of the rescue treatments in patients who fail to respond to conventional therapies. With the accumulation of experience and advances in technology, the application of VV-ECMO has been extended from viral or bacterial pneumonia to other causes of respiratory failure. The number of adult patients receiving this therapy substantially increased following the CESAR trial. One key principle of patient selection is the underlying disease reversibility. The VV-ECMO procedure should be regarded as temporary lung support that serves as a bridge to disease recovery or transplantation. Individual ECMO centres may develop their own inclusion and exclusion criteria based on availability of expertise, resources, and supporting services. Of note, ECMO is not risk free. Understanding the equipment physiology, configuration, and potential complications is essential for its safe application. Meticulous monitoring combined with appropriate patient management is crucial to the success of VV-ECMO in ARDS patients.

\section{References}

1. Gibbon JH Jr, Hill JD. Part I. The development of the first successful heart-lung machine. Ann Thorac Surg 1982;34:337-41.

2. Hill JD, O'Brien TG, Murray JJ, et al. Prolonged extracorporeal oxygenation for acute post-traumatic respiratory failure (shock-lung syndrome). Use of the Bramson membrane lung. N Engl J Med 1972;286:629-34.

3. Hill JD, De Leval MR, Fallat RJ, et al. Acute respiratory insufficiency. Treatment with prolonged extracorporeal oxygenation. J Thorac Cardiovasc Surg 1972;64:551-62.

4. Extracorporeal Life Support Organization. ECLS registry 
report, international summary 2017. Available from: https:// www.elso.org/Registry/Statistics/InternationalSummary. aspx. Accessed Jan 2017.

5. Chauhan S, Subin S. Extracorporeal membrane oxygenation, an anesthesiologist's perspective: Physiology and principles. Part 1. Ann Card Anaesth 2011;14:21829.

6. Holzgraefe B, Broomé M, Kalzén H, Konrad D, Palmér $\mathrm{K}$, Frenckner B. Extracorporeal membrane oxygenation for pandemic H1N1 2009 respiratory failure. Minerva Anestesiol 2010;76:1043-51.

7. Ventilation with lower tidal volumes as compared with traditional tidal volumes for acute lung injury and the acute respiratory distress syndrome. The Acute Respiratory Distress Syndrome Network. N Engl J Med 2000;342:13018.

8. ELSO adult respiratory failure supplement to the ELSO general guidelines. Version 1.3. Ann Arbor, MI: Extracorporeal Life Support Organization; 2013.

9. Peek GJ, Mugford M, Tiruvoipati R, et al. Efficacy and economic assessment of conventional ventilatory support versus extracorporeal membrane oxygenation for severe adult respiratory failure (CESAR): a multicentre randomised controlled trial. Lancet 2009;374:1351-63.

10. Australia and New Zealand Extracorporeal Membrane Oxygenation (ANZ ECMO) Influenza Investigators, Davies A, Jones D, et al. Extracorporeal membrane oxygenation for 2009 influenza $\mathrm{A}(\mathrm{H} 1 \mathrm{~N} 1)$ acute respiratory distress syndrome. JAMA 2009;302:1888-95.

11. Pham T, Combes A, Rozé H, et al. Extracorporeal membrane oxygenation for pandemic influenza $A(\mathrm{H} 1 \mathrm{~N} 1)$ induced acute respiratory distress syndrome: a cohort study and propensity-matched analysis. Am J Respir Crit Care Med 2013;187:276-85.

12. Patroniti N, Zangrillo A, Pappalardo F, et al. The Italian ECMO network experience during the 2009 influenza $\mathrm{A}(\mathrm{H} 1 \mathrm{~N} 1)$ pandemic: preparation for severe respiratory emergency outbreaks. Intensive Care Med 2011;37:144757.

13. Extracorporeal membrane oxygenation for severe acute respiratory distress syndrome (EOLIA). Available from: https://clinicaltrials.gov/ct2/show/NCT01470703. Accessed Dec 2016.

14. von Bahr V, Hultman J, Eksborg S, Frenckner B, Kalzén H. Long-term survival in adults treated with extracorporeal membrane oxygenation for respiratory failure and sepsis. Crit Care Med 2017;45:164-70.

15. Lewandowski K. Extracorporeal membrane oxygenation for severe acute respiratory failure. Crit Care 2000;4:15668.

16. Vasilyev S, Schaap RN, Mortensen JD. Hospital survival rates of patients with acute respiratory failure in modern respiratory intensive care units. An international, multicenter, prospective survey. Chest 1995;107:1083-8.

17. Pranikoff T, Hirschl RB, Steimle CN, Anderson HL 3rd, Bartlett RH. Mortality is directly related to the duration of mechanical ventilation before the initiation of extracorporeal life support for severe respiratory failure. Crit Care Med 1997;25:28-32.

18. Murray JF, Matthay MA, Luce JM, Flick MR. An expanded definition of the adult respiratory distress syndrome. Am Rev Respir Dis 1988;138:720-3.

19. Formica F, Avalli L, Martino A, et al. Extracorporeal membrane oxygenation with a poly-methylpentene oxygenator (Quadrox D). The experience of a single Italian centre in adult patients with refractory cardiogenic shock. ASAIO J 2008;54:89-94.

20. Kohler K, Valchanov K, Nias G, Vuylsteke A. ECMO cannula review. Perfusion 2013;28:114-24.

21. Tremblay LN, Slutsky AS. Ventilator-induced lung injury: from the bench to the bedside. Intensive Care Med 2006;32:24-33.

22. Hickling KG, Walsh J, Henderson S, Jackson R. Low mortality rate in adult respiratory distress syndrome using low-volume, pressure-limited ventilation with permissive hypercapnia: a prospective study. Crit Care Med 1994;22:1568-78.

23. Amato MB, Barbas CS, Medeiros DM, et al. Effect of a protective-ventilation strategy on mortality in the acute respiratory distress syndrome. N Engl J Med 1998;338:34754.

24. Ng GW, Leung AK, Sin KC, et al. Three-year experience of using venovenous extracorporeal membrane oxygenation for patients with severe respiratory failure. Hong Kong Med J 2014;20:407-12.

25. Meade MO, Cook DJ, Guyatt GH, et al. Ventilation strategy using low tidal volumes, recruitment maneuvers, and high positive end-expiratory pressure for acute lung injury and acute respiratory distress syndrome: a randomized controlled trial. JAMA 2008;299:637-45.

26. Mercat A, Richard JC, Vielle B, et al. Positive end-expiratory pressure setting in adults with acute lung injury and acute respiratory distress syndrome: a randomized controlled trial. JAMA 2008;299:646-55.

27. Gattinoni L, Caironi P. Refining ventilatory treatment for acute lung injury and acute respiratory distress syndrome. JAMA 2008;299:691-3.

28. National Heart, Lung, and Blood Institute Acute Respiratory Distress Syndrome (ARDS) Clinical Trials Network, Wiedemann HP, Wheeler AP, et al. Comparison of two fluid-management strategies in acute lung injury. $\mathrm{N}$ Engl J Med 2006;354:2564-75.

29. Lin CY, Chen YC, Tsai FC, et al. RIFLE classification is predictive of short-term prognosis in critically ill patients with acute renal failure supported by extracorporeal membrane oxygenation. Nephrol Dial Transplant 2006;21:2867-73.

30. Smith AH, Hardison DC, Worden CR, Fleming GM, Taylor $\mathrm{MB}$. Acute renal failure during extracorporeal support in the pediatric cardiac patient. ASAIO J 2009;55:412-6.

31. Yan X, Jia S, Meng X, et al. Acute kidney injury in adult postcardiotomy patients with extracorporeal membrane oxygenation: evaluation of the RIFLE classification and the Acute Kidney Injury Network criteria. Eur J Cardiothorac Surg 2010;37:334-8.

32. Chen H, Yu RG, Yin NN, Zhou JX. Combination of extracorporeal membrane oxygenation and continuous renal replacement therapy in critically ill patients: a systematic review. Crit Care 2014;18:675.

33. Santiago MJ, Sánchez A, López-Herce J, et al. The use of continuous renal replacement therapy in series with extracorporeal membrane oxygenation. Kidney Int 2009;76:1289-92.

34. Symons JM, McMahon MW, Karamlou T, Parrish AR, McMullan DM. Continuous renal replacement therapy with an automated monitor is superior to a free-flow 
system during extracorporeal life support. Pediatr Crit Care Med 2013;14:404-8.

35. Harthan AA, Buckley KW, Heger ML, Fortuna RS, Mays K. Medication adsorption into contemporary extracorporeal membrane oxygenator circuits. J Pediatr Pharmacol Ther 2014;19:288-95.

36. Lemaitre F, Hasni N, Leprince P, et al. Propofol, midazolam, vancomycin and cyclosporine therapeutic drug monitoring in extracorporeal membrane oxygenation circuits primed with whole human blood. Crit Care 2015;19:40.

37. Nader-Djalal N, Khadra WZ, Spaulding W, Panos AL. Does propofol alter the gas exchange in membrane oxygenators? Ann Thorac Surg 1998;66:298-9.

38. Oliver WC. Anticoagulation and coagulation management for ECMO. Semin Cardiothorac Vasc Anesth 2009;13:15475.

39. ELSO anticoagulation guidelines 2014. Ann Arbor, MI:
Extracorporeal Life Support Organization; 2014.

40. Pollak U, Yacobobich J, Tamary H, Dagan O, ManorShulman O. Heparin-induced thrombocytopenia and extracorporeal membrane oxygenation: a case report and review of the literature. J Extra Corpor Technol 2011;43:512.

41. Sanfilippo F, Asmussen S, Maybauer DM, et al. Bivalirudin for alternative anticoagulation in extracorporeal membrane oxygenation: a systematic review. J Intensive Care Med 2016 Jun 29. Epub ahead of print.

42. Ranucci M, Ballotta A, Kandil H, et al. Bivalirudinbased versus conventional heparin anticoagulation for postcardiotomy extracorporeal membrane oxygenation. Crit Care 2011;15:R275.

43. ELSO general guidelines for all ECLS cases. Version 1.3. Ann Arbor, MI: Extracorporeal Life Support Organization; 2013. 